\title{
Art, Values, Institutions and Culture: An Essay in American Studies Methodology and Relevance
}

I SEE SEVERAL WAYS IN WHICH THE ARTS CAN BE USED IN CULTURE STUDIES; each way suggests appropriate methodologies. ${ }^{1}$ But my concern in this essay is primarily with art as an institution-or as a group of institutions - and I propose to sketch out a tentative method for this approach, one which sees the arts as a group of institutions among many and which may be used to get at basic cultural values.

The approach to arts, values, institutions and culture which I am going to outline is by no means original to me. ${ }^{2}$ I like to think that it is the result of a process which ought to work upon any scholar involved in an interdisciplinary field. I work with many students and colleagues trained in

'Several may be briefly listed: 1) Art-as-prophecy. For all that social scientist friends scoff at the idea, I believe that artists sometimes sense directions in which things are going before the rest of us do. The method suggested is simple chronicling, using anecdotal evidence. Such evidence, of course, can't prove that art foreshadows change (art may, after all, help cause change), but it can prove that change is rapid, common and expected in our society. The fact that the process would not work as well in cultures which change less rapidly, or in which the artist is less differentiated from his fellows, is in itself significant. 2) Arts-as-artifact. The method one uses to read artifacts is archaeological, and procedures are firmly established. 3) Art as a source of data about language, human relations, social structures, about what Edward Hall calls "silent language" (The Silent Language, New York: Doubleday, 1959), and about basic story-types which tell us how experience is organized or perceived ("myth" is not too strong a word for such patterns). Such data are most readily obtained from substantive arts; the basic method used is content analysis, though other methods will work providing the end is sechel, not aesthetic evaluation.

${ }^{2}$ To some extent, for instance, my line of reasoning has been influenced by students who took their cue from Richard E. Sykes' article "American Studies and the Concept of Culture: A Theory and Method" (American Quarterly, 15 [Summer 1963], 253-70), which I hadn't read myself until very recently. 
fields very different from those in which I was trained, and over the years they have gradually pushed me in the direction in which this paper goes. I in turn have pressed them to try out the ideas we had arrived at on more and more evidence. And for the past two years I have brought our tentative conclusions to the attention of colleagues at scholarly conventions, to see whether the hypotheses which my students and I have gradually developed seemed useful to them. ${ }^{3}$ Colleagues urged me to put these ideas together in some accessible place, and that is the real reason behind the present essay.

It is probably worth mentioning that on both occasions in which I presented these ideas, some people in the room misunderstood them, taking them to be an attack on the elite arts, a kind of cynical and even snide put-down of humanists on the part of a social scientist dabbling in the arts. That is not what I intend at all. If my readers will excuse a little confessional material, let me say that I have no training in the social sciences beyond what my students have taught me, that for many years I made my living teaching American literature and the history of American painting, that I also have training in American architecture and American music, and that for a number of years before entering the academic world I supported myself as a professional concert musician. I still love all these arts, still perform from time to time, still spend happy hours in museums and concert halls.

Very often in American Studies one finds oneself, at last, engaged in analysis of one's own feelings and values. That is as it should be. On the one hand, one wants the kind of detachment which an outsider to our culture would bring to a study of the United States; on the other hand, one has advantages in studying it which he will never have, the results of a lifetime of living as an American, increasingly sensitive to all manner of nuances, social cues and associations, which, taken together, form a kind of cultural code almost impossible for an outsider to crack. Ideally one wants both familiarity and detachment. Thus if, in this essay, I point out that an art, let us say, is valued partly for reasons which are not cosmic truths, but are rather the result of certain peculiarities in the way in which our culture operates, this does not mean that I do not myself value the art. I find, on the contrary, that I carry many of the values described in this essay. But I refuse to believe that it is bad to attain sufficient detachment from them to recognize them for what they are-attitudes I hold, values by which I make judgments, but not necessarily universal truths.

\footnotetext{
3"Towards a General Theory of Elite Art and Culture," paper delivered at the second national meeting of the American Studies Association, Toledo, Ohio, Oct. 1969; informal remarks delivered during an open discussion of the arts at the 20th Annual Meeting of the Midcontinent American Studies Association, March 1970.
} 
A Model for Institutions, Value Systems and Artifacts: Let us begin by playing social scientist and talking about the relationships indicated in Figure 1. If this chart is read from left to right, the movement represents a progression from characteristics which are true of all people down to the specific things which people in a given culture or subculture actually produce. You will note that the left side of the figure is labeled, "Universals about Human Nature-from Psychology, Philosophy, Religion, etc." I have deliberately left matters vague because what I have in mind throughout this paper is not imposing my thinking on anyone, but rather providing a framework for the thinking of others. All that I mean by that left-hand side of the chart is, "Whatever you feel is universally true about people." This means all people, not just Americans or people in western culture in general. Given readers might feel that their opinions are rooted in biology, psychology, philosophy, religion or, more likely, a combination of such fields. The arts themselves might very well be included; many teachers of literature, for instance, feel that it is preferable to science or social science as a source of information about what all people are. I would only urge that a reader who wants to make use of this diagram be sure that his definition of basic human characteristics is sufficiently universal to cover all people, and not merely people in our culture, or in closely related cultures.

Hunger and sexual drive, I would imagine, would be present, along with certain other "basic" factors, on everyone's list of behavioral determinants. They seem to be human, not cultural. Certain others might be present or not, depending upon the observer's opinion. For instance, the two recent popularizing books of Robert Ardrey ${ }^{4}$ have convinced many people that territoriality and the need for violence are universal human characteristics. If one agrees, those determinants would go on the list. If one disagrees, they would not. Their presence could affect the way one used the entire scheme represented by Figure 1.

Moving to the right, we come to institutions. At this point we have left the realm of "things that are true of all people" and entered, so to speak, the United States. Here again I want to allow the reader as much leeway as possible in deciding which institutions he might want to list, and about how "institution" is to be defined. Indeed, I hestitate to use the word "institution" because it has a fairly clear and precise meaning to social scientists, a meaning rather more limited than what I intend. I want to leave the way open to examine not only the institution as a whole, but also any functioning portion of it, or even an individual operating in a role defined

${ }^{4}$ Robert Ardrey, The Territorial Imperative (New York: Atheneum, 1966); The Social Contract (New York: Atheneum, 1970). 


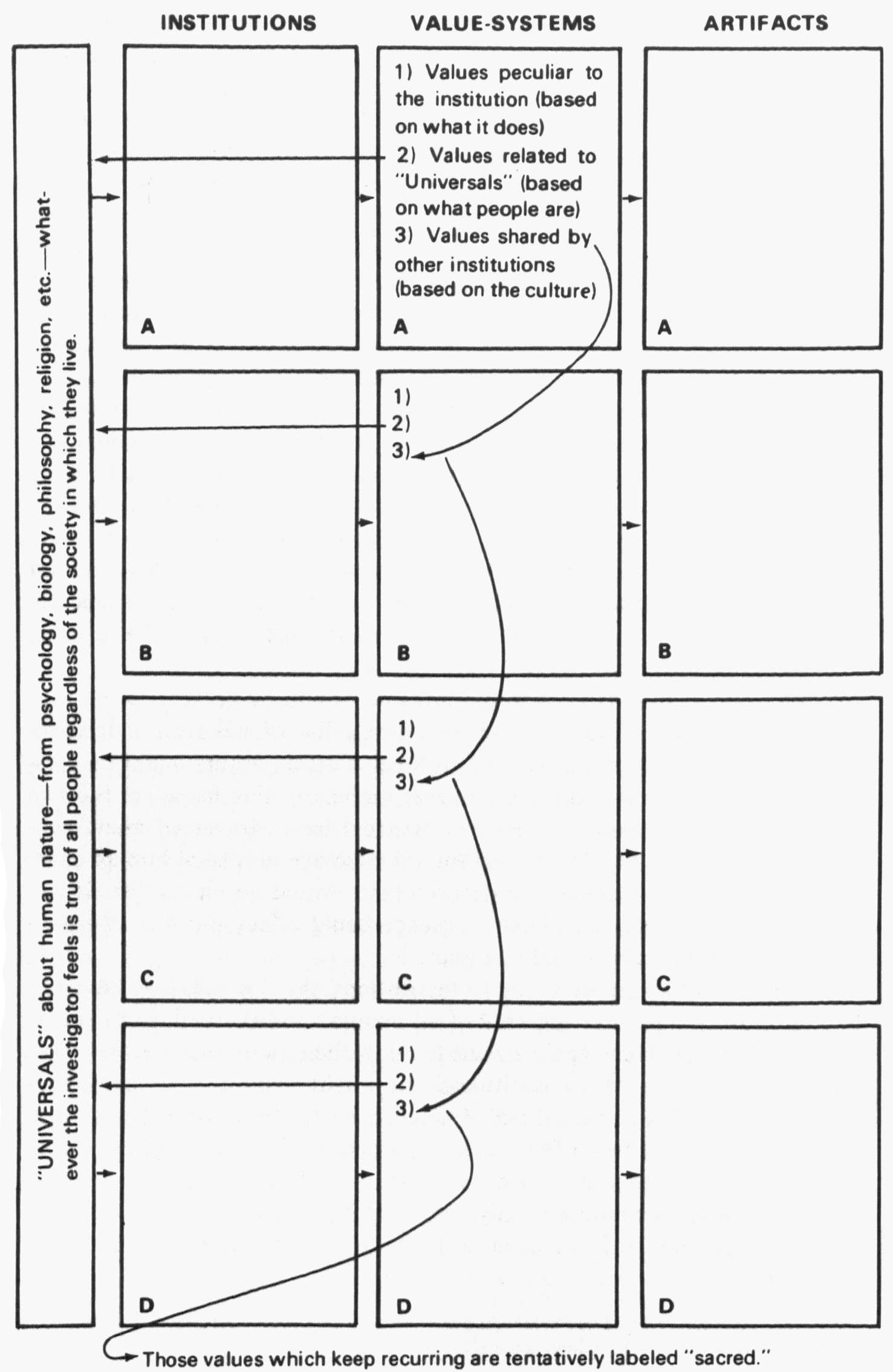

Figure 1. Institutions, Values and Sacred Values. 
by it. I think that the scheme is flexible enough, for example, so that if one wanted to use Institution A to represent, let us say, "industry," this would be fine; it would also be all right to interpret it in a much more specific way, so that Institution A means "the food industry," "a given cannery in a given city" or even "the Board of Directors of a given cannery in a given city." So, in utilizing this scheme, one could fill in the blank space represented by the square labeled "Institution A" with headings as different as "the family" or a specific family; "government" or a specific part of government; "Higher education" or a specific institution of higher education, a specific portion of that institution or even a given class taught by a specific professor to a group of specific students and covering some specific material. I am aware that such a class is not what a sociologist would call an institution. "Education" or "higher education" perhaps would fit his definition better, and the specific class would simply be an organized subdivision functioning within the larger institution. But I am going to call it an institution anyway, because it reveals values, produces artifacts and might, in a given instance, be easier to analyze than higher education as a whole.

It will be noted that one can say something about the relationship between institutions and the universal characteristics of human nature at the left of the chart. For example, should we really want to discuss a cannery, we know that canneries can food, and that philosophers, psychologists and theologians would all agree that all people have to eat. Other basic human characteristics might also be represented in the cannery. If you have been reading Reinhold Niebuhr recently, for example, you might believe that "the will to create" and "the will to power" are basic components of human nature, and you might see both operating, in the ambiguous and overlapping manner which Niebuhr describes, in the person, let us say, of a given administrator of the factory.

But two observers might disagree about the relationship between basic drives and institutions. If you are examining an organized sport, and feel that it reflects the competitiveness of the society, that competitiveness would seem to be cultural. But if, on the other hand, you feel that all people are by nature competitive, then the sport might seem to be just the way one culture provides a social arena for a universal drive. It would still be true that certain institutions appear in certain cultures and not in others. That fact is the key to the method I am proposing, to enable us to get from observable characteristics of a culture to underlying values.

When I have asked social scientists about values, they have usually told me to look to the institution. The concept of cultural values seems to be somewhat suspect today among sociologists and anthropologists. They seem discouraged by the existence of contradictory values within the same 
societies, particularly complex societies such as ours, but they agree that institutions themselves have value systems. Being a humanist, and so perhaps less dismayed by the messy complexities of behavior in complex societies, I have taken what they say about institutional value systems as a clue to how one might tackle cultural values. ${ }^{5}$ I should think that the values one finds within a given institution could be divided into various headings, and I have suggested these headings in the chart: those peculiar to the nature of the institution; those related to our "universals" about human nature; and those shared by other institutions within the culture. ${ }^{6}$ To use our example of the cannery once again, it might be, for example, that the people who operate it could be shown to associate such values with it as profit, enterprise, power, service, perhaps even creativity. And since the place is a cannery, they might also stress fairly specialized values, such as cleanliness, uniformity and efficiency. Even aesthetic considerations might appear; they might get more than commercial pleasure out of producing plump-looking peas of the right shade of green in an attractively designed can. Moreover, they might regard their executive roles as creative or even artistic; I have no doubt that many businessmen play upon their organizations as upon an organ. Now, some of these things might appear only in the value systems of given people within the cannery. An assembly-line worker might feel very different than does a given cannery executive, so one would have to be fairly careful in defining whose values were under discussion. But I think that once such a definition were made, it would be relatively easy to arrive at a list of values.

On the right-hand side of Figure 1 are a series of boxes labeled "artifacts." The assumption here is fairly simple. Most human institutions produce something or leave some sort of record which a student of the culture might study, and which might give clues to the nature of the institution and to its value system. Artifacts, like the institutions which pro-

\footnotetext{
${ }^{5}$ A perceptive editorial reader for American Quarterly notes that in several places this essay moves close to areas in which social scientists have done distinguished work, and suggests that if my conclusions were reached independently, that point is in itself important, and should be mentioned, for it would suggest that certain approaches and conclusions have so much validity that men working from entirely different angles of attack would reach them. Such is the case here. He suggests that my argument in this portion of the essay be compared to Evon Zartman Vogt, The People of Rimrock: A Study of Values in Five Cultures (Cambridge: Harvard Univ. Press, 1966), to Franz Adler, "The Value Concept in Sociology," American Journal of Sociology, 62 (Nov. 1956), 272-79, in Nicholas Reschner, Introduction to Value Theory (Englewood Cliffs, N.J.: PrenticeHall, 1969), and Harold Fallding, "A Proposal for the Empirical Study of Values," American Sociological Review, 30 (Apr. 1965), 223-33.

"The same reader (see note 5) suggests that my scheme here "is very close to that of Bronislaw Malinowski in his $A$ Scientific Theory of Culture" (A Scientific Theory of Culture and Other Essays [Chapel Hill: Univ. of North Carolina Press, 1944]), and again recommends that the reader compare the two.
} 
duce them, are observable characteristics. Our pea canning factory, obviously, produces cans of peas. They are good artifacts, worthy of study. We might also consider the factory itself, or the entire production system, as artifact. This type of artifact could tell us things about the level of technology, methods of organization, the economic system, the transportation system and so on.

In the absence of other evidence, we would have to depend entirely upon artifacts, as we do when we try to learn about civilizations of ancient times. In studying our own culture, of course, we have access to all manner of data. If we want to know what a manufactured item is used for, for instance, we can ask and find out. But I include artifacts on the chart because I want to suggest that it is wise, in culture studies, to attain the kind of detachment which an archaeologist feels as he studies an ancient piece of pottery. We are surrounded by artifacts of our own culture; it is difficult to see them as evidence one could use to describe us. They are, and can help us achieve necessary distance and perspective.

To enable us to move from institutions and artifacts to values and sacred values, I propose the following hypothesis: values which recur in a wide variety of institutions in a given culture must be either universal-present, that is, among all people in all cultures-or somehow "sacred" within the culture. They are not merely reflections of the peculiarities of the institution; they seem rather to be the most highly condoned formulation of the world-view by which the culture operates. I am by no means positive that this is true, but it does suggest a method for defining and deriving sacred values, and the method seems to work. If we examine a wide range of institutions in our society, and for each do a conscientious job of compiling a list of values, then scan the lists to determine patterns of recurrence, I believe we will be left with a relatively small number which appear to be basic. Which of these one calls "universal" and which "sacred" will often depend on how one defines universal human characteristics, but the distinction is less important than the fact that a list of recurring items will result. If one really wanted to sharpen that distinction, one could repeat the procedure for the values of other cultures, as diverse and as alien to one another as possible, and see which values show up in all. It seems reasonable to guess that those which always appear are universal. The residue would seem to be sacred only in given cultures; they would be different from one culture to the next.

The procedure should be very useful in cross-cultural studies. It should also be applicable within a specific society, such as ours, to help us understand the relations between subcultures. I would think that any group in our society which seemed to adhere to the list of recurring values could safely be labeled "subculture," no matter how different it otherwise ap- 
peared to be from whatever is taken to be "typical" or "characteristic." And I would think that if one found a group which did not possess these values it could be labeled "alien," even though its members occupied the same geographic area.

I am calling those values which recur "sacred" values, by which I mean things which seem so basically true to people in a culture that not only are they seldom really challenged, they form a basis of thought and evaluation. One might call them-although the phrase is awkward-the "nonuniversal sources of human thought and behavior." You will see that "nonuniversal" comes to mean something pretty close to "cultural."

Let us review this scheme briefly. What I am suggesting is that if we add up those values which we find in a wide variety of institutions within a given culture, and cross off all of these which do not recur or are considered universal, we will be left with something which we might call the sacred value system of the culture. "Sacred" does not refer in this sense to specifically religious institutions or values. It might be, for example, that in a culture such as ours, in which religion is often considered to be a separate category of human concern and activity, that "sacred" would appear to be more sacred (or more basic) than specific values or beliefs adhered to by a given religious body.

An example will perhaps help make this point clear. In Harold Frederic's novel The Damnation of Theron Ware, Theron, a naive but gifted young Methodist minister, has a conversation with a pair of sophisticated intellectuals, a Catholic priest and a doctor who is a scientific amateur of some scholarly standing. "I dare say," says the priest, ". . . that if we could go back ... scores of centuries, we should find whole receding series of types of this Christ-myth of ours." Theron's initial reaction is panic; he gives "a swift, startled look about the room, the instinctive glance of a man unexpectedly confronted with peril and casting desperately about for means of defense and escape." His fear, however, lasts for only a moment, for he recognizes that he is in the room with urbane men who have access to a great deal more in the way of "scientific" kinds of knowledge than he does. The most sacred (in the religious sense) "truth" in his religious training has just been challenged, but apparently Theron feels that there is a truth even higher. We might say that for him, scientifically verifiable "truth" seems more sacred than religious "truth."

If one went through the analytical process outlined in the "Value System" portion of Figure 1 and succeeded in compiling a list of "sacred" values, it might be that one would notice that some of the institutions one had used in the course of one's investigation seemed unusually rich in "sacred" values and relatively weak in more mundane or "practical" values. Let us postulate that one will find in human societies institutions 
which have as a prime purpose the reinforcement of the most sacred values of the culture. They do not exist, if we are right, simply to satisfy material or "practical" needs.

In a culture as complex and diverse as our own, I think it unlikely that such sacred institutions will be the same for everyone. Different people or groups use different institutions, and I am making an educated guess that they will use different sacred institutions. A given American, let's say, participates in a large business firm, in two organized social and service clubs, in an informal social circle of friends who live in widely separated parts of the town, in a church. He makes use also of certain artistic and recreational institutions; perhaps he likes certain kinds of music, plays golf and follows a favorite football team. His neighbor perhaps is involved in not one of the institutions named; he is, let us say, self-employed, dislikes lodges and service clubs, socializes primarily with friends in the immediate neighborhood, is active only in a political organization, enjoys gardening, has no interest in music or religion and, while he never watches football, follows his son's high school basketball team avidly. Racial background is an important determinant in the list of institutions which a third person in the town utilizes. He is, let's say, Chicano, a laborer, socially close to a large family of a sort his neighbors do not have; he attends a Catholic church, but infrequently, and a neighborhood bar is important to his social life. One could go on indefinitely making up patterns of use and participation. The student of an isolated tribal culture would have no such problems; the more communal patterns of tribal life would provide a far more uniform list.

Given the bewildering variations of our society, it would be extremely useful to find key institutions which serve similar purposes for different people. If we could determine which of the institutions we use are sacred, we would have a useful means of simplifying our examination of values. Such a shortcut would be invaluable; the problem of culture study is so complicated that any shortcuts are welcome.

How to determine which institutions are sacred? A tough issue; I can do no more than offer some rather speculative criteria. This portion of my scheme is frankly tentative. I am by no means sure that it is correct, but I can say that it seems to work, to yield results which have been useful to me and to my students in figuring out fruitful approaches to cultural values. Let me illustrate the kinds of criteria I have used by starting with an example far removed from American culture.

A colleague of mine, not himself an anthropologist, spent a year in Australia, much of it with aboriginal people. He came to know several aborigines well, and witnessed a number of ceremonies. His observations were of interest to anthropologists, and I was present on several occasions 
when things he had seen were discussed informally. If a ceremony involving dancing and totemic objects was used, let's say, to obtain guidance before a trip in search of food, or to influence the weather, the professional students of such matters would ask for details, and then compare the ritual to others they knew in other tribal societies. The ceremonies were certainly sacred in that they involved the people's conception of a world guided by magic, "influence," the intervention of long dead ancestors, and totemic forces. But apparently "sacred" is a relative thing, for these rites were clearly practical too, in that they involved everyday needs, food and rain, for instance. There was another sort of ceremony for which my friend's descriptions seemed less satisfactory. When he asked his aboriginal informants for explanations, he could obtain only vague responses, statements to the effect of, "It's hard to explain this one, but if you were one of us, and did it, then you would understand." Or, "This is to make my grandfather (long dead and associated with a totemic animal) more comfortable." Or, "We always do this because it's very good for you."

One of the anthropologists remarked that one never really "cracks" a culture until one understands these most puzzling observances. There followed a general discussion of puzzlers one or another of them had encountered in field trips, and of whether social scientists aren't overly optimistic when they claim to be able to understand alien cultures. A consensus opinion was that while any ritual expressed a tribe's belief and cosmology, these especially puzzling ones did so in a particularly pure form: indeed, that is all that they seemed to do. Even their undeniable social and aesthetic aspects were related to the unspoken cultural truths of tribal being. Even more than the others, they deserved the label "sacred." "Sacred," then, seems to refer to that area which has as its most important function the expression and reinforcement of basic truths and assumptions.

A Model for Sacred Value Systems: Where would one look in our culture for institutions which seem comparably "sacred"? What we are looking for are institutions which are justified in terms rather similar to those which the aborigines in the anecdote used to describe their most baffling ceremonies. Apparently they should be felt to be good for you, but in ways which are a little difficult to define for an outsider. They might be expected to build desired traits of personality or to be good in themselves simply because of the nature of things. One might look for clues of the sort which my friend brought back from Australia: if you asked someone who used one of these institutions why he thought it was a good thing, he might have to answer you by saying, "Well, that's a little hard to describe, but if you were involved in it, you would see." All of this is very 
vague and quite negative, but it seems to me that the negative quality is important. When one deals with things so fundamental that they have become practically a part of personality, one may expect people to have trouble defining them. They key positive test, I would suppose, for sacred institutions in our culture is that they serve as a kind of morality play for those recurrent values which we are tentatively labeling "sacred."

I have been posing this kind of a problem to my classes for the past three years, and we have followed approximately the line of reasoning I have described. We began by laying out an overall strategy which we hoped would be manageable in scope, then selected a large number of institutions and compiled lists of values which pertained to each. We tried to achieve as much diversity as possible, selecting institutions from areas as different as business, industry, government, the arts, athletics and religion. We looked also at the family (through studies of it), to social and service clubs and even to institutionalized hobbies. Some were analyzed on the largest scale, others through smaller units. Comprehensiveness, of course, was impossible to attain; we tried for range.

Next, we listed the swarm of values we thought we had uncovered and crossed off those which seemed peculiar to the nature of given institutions. Then we marked off those which did not seem to recur throughout. For example, we found basketball coaches talking about "quickness" and "speed," values which seem peculiar to certain sports. "Profit" showed up as a value in many institutions, but not nearly in all, so it was marked off because it did not recur enough. There was a residue which seemed worthy, at least tentatively, of the label "sacred."

Finally, we went back over the list of institutions and their value systems to see which seemed "purest" in that they appeared to function largely to reinforce the value system. We sought those whose value systems most nearly approximated our tentative list of "sacred" values. Undoubtedly the group we decided to examine in detail was determined partly because of the interests of the students; undoubtedly also our original motivation-to develop a firm methodology for using the elite arts in culture study-played its part in determining items in the list. The group we decided on-organized athletics, the fine arts, education and research-does not seem to me to be all-inclusive by any means, but it seems useful and in some ways surprising. Understand that no one is claiming that these institutions function as "sacred" for all people in our culture. All that is suggested is that they perform a sacred function for those who use them. The reader will perhaps think of others which function in a similar manner. Why, one might ask, are the elite arts listed, and not popular arts? Are the latter not more "representative" because more widely used? For the moment, suffice it to say that some of our group did work on more "popular" art 
forms, but that representativeness seemed less crucial to us than the degree of sanction with which institutions operate, and that, besides, we were out to discover ways of handling elite arts. The popular arts, so far as we treated them, seemed to follow many of the same patterns as did elite arts, but with a far less clearly developed system of sanctions and validations. They were also very hard to work with. Still, they are too important to ignore, and will be discussed in passing as we go on.

To make clear how our scheme works, let us discuss the four institutions we examined in detail in terms of the diagram in Figure 2. Figure 2 is just an enlargement of Figure 1. The left side still represents universal human characteristics; next, institutions; then, value systems; then, artifacts. The scale has been changed to allow more space in which to write hypothetical characteristics of the value system of a sacred institution. Let us say, for the moment, that the institution with which we are dealing is professional baseball. Certainly baseball has some values peculiar to itself. These relate largely to techniques and skills involved in the game. Then it certainly carries some values which relate to "universals." For example, if you believe that it is a universal human characteristic to desire to have a strong and gratifying group identification, then this might explain the satisfaction which fans get from associating with a team. If you believe that territoriality is a basic human characteristic, it too may be involved; the team might be felt, symbolically, to defend the city it represents. If your analysis of human character includes some category dealing with the need to engage in combat or conflict, even in a vicarious manner, this too might be listed. Note, however, that the institution of professional baseball has no "physical" or "practical" relationship to human needs. It does not can peas or build houses.?

When one looks to see how it is justified, one does in fact encounter a cluster of values which do recur in other institutions. Achievement, for example, is valued. If we hear a story about a very talented ballplayer whose career is cut short by an injury, by a scandal in which he was tempted, let us say, by a group of gamblers, or by any other sort of misfortune, the story seems to us sad. On the other hand, a story about talent which fulfills itself strikes us as happy. These two patterns are so basically understood that they form the basis for most of our sports fiction and for most of the vast number of articles and books about real sports figures of the past. Two basic truths emerge from the patterns: individual talent is real; achievement is good. But note that these are cultural, not universal,

'It does, of course, provide a livelihood for ballplayers and stadium employees. As in our pea cannery, values may vary depending on whom in the institution one considers. And baseball, like the arts, certainly has an abstract aesthetic dimension to be considered also. 


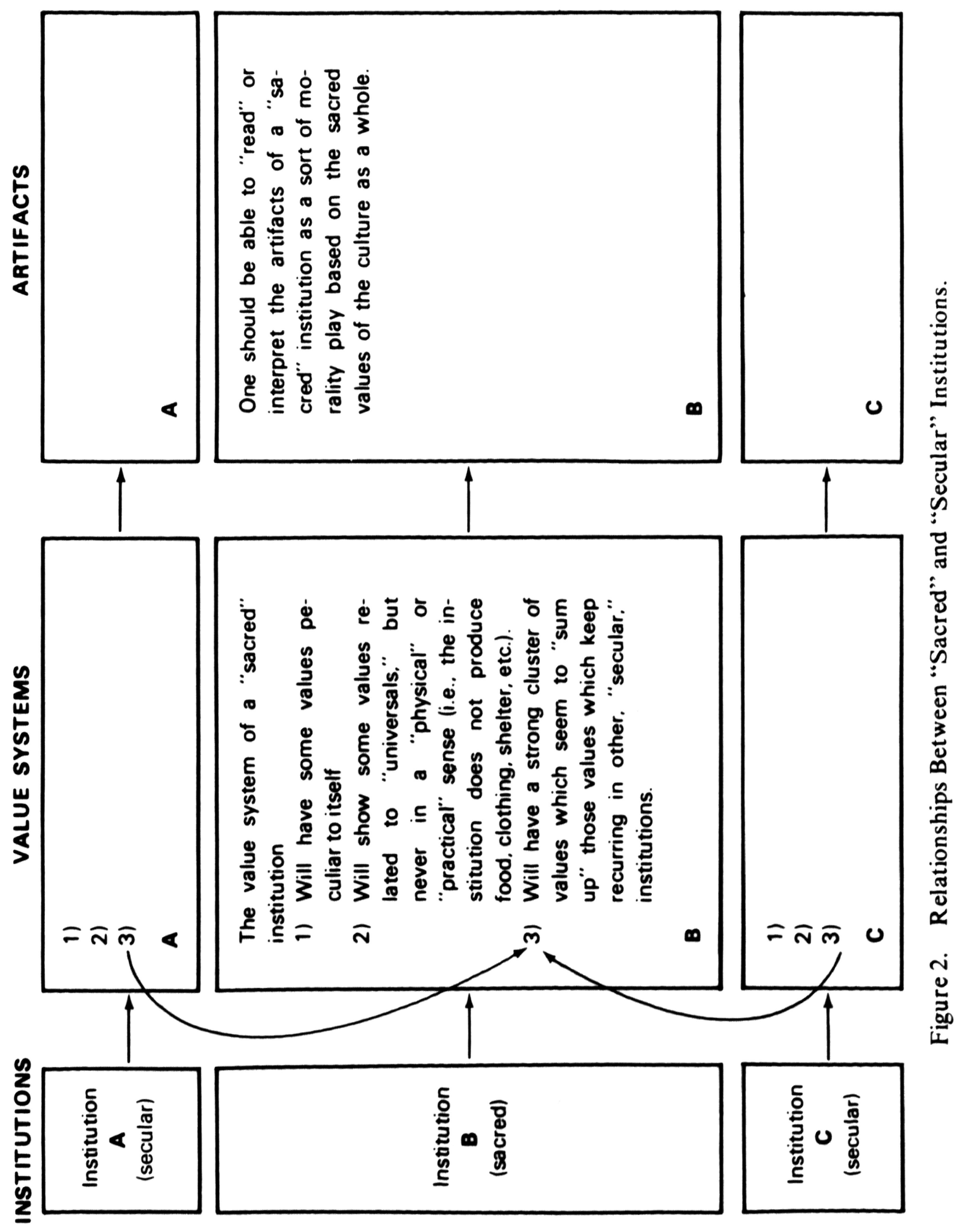

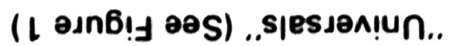


truths. In many other cultures, basic biographical patterns often are built not on a rise in status based upon the fulfillment of talent, but rather upon, let us say, achieving harmony within a pre-existing system.

Speaking on a different topic to a class of mine, Archie Eteeyan, an Indian leader from Topeka, provided a fine example of people who do not stress achievement or individual talent. His anecdote follows: "You all know Indian kids are good at sports. But their parents tell 'em, 'You don't want to win by too much. Don't make yourself too big.' So the Indian kid runs the race, and he could win by a mile. But he looks back, and he slows up, so he won't beat the white kids by too far. When a white kid is fast, you see, he goes as fast as he can. He runs against the clock." Mr. Eteeyan reinforced his story with anecdotes about the shyness of groups of Indian people in formal situations involving whites. The "shyness" is the result, often, of each individual's feeling that he should not take upon himself the role of leader or spokesman of the group, and is based upon a set of cultural values different from those of "anglos."

Community leaders in major cities will tell one that it is important for the city to have a major league team. They couch their arguments not only in terms of providing entertainment for the citizens, but more importantly in terms of a kind of status which it is felt the presence of a team, especially a successful team, confers upon the community, and by implication, upon all of its citizens. One scores points in heaven, somehow, by having a team. Indeed, one often is made to feel that one has a duty to attend some games, even if the team is having a poor season.

If individual achievement is stressed, so is "teamwork," a rather complex concept which seems to me to embody some very basic facets of the postRenaissance western mind. An organization of almost any sort is felt to be properly structured when it is made up of a number of highly skilled specialists whose functions are neatly compartmentalized, yet who can and do function together as a team. The idea is so basic that we seldom think of it as an idea. It simply strikes us as reasonable to approach any problem through analysis - that is, by breaking it down and attacking each phase of it through specialized techniques. Baseball, along with many other sports, might be thought of as a morality play for this process.

Related to specialization and achievement is "dedication" or "involvement." A coach or another member of a team will often praise a player for his dedication, which seems to mean his devotion to the process of perfecting specialized skills. It is something good one can say about a boy whose athletic talents are not otherwise notable. I was struck by the manner in which this same quality was stressed in a very different situation, not involving sports, when I attended a meeting of a regional Harvard College Schools Committee. Our job is to encourage promising high school 
seniors to apply for admission to Harvard. The agent with whom we met reported to us the criteria which the Admissions Office uses, and "involvement" or "dedication" was stressed. "It may not mean much that a boy was president of his class. But if he organized a discussion group in his church, founded a literary magazine in school, worked in a political campaign, made himself an accomplished musician - that shows dedication, and they are liable to let him in."

Foreigners who are taken to baseball games, or Americans who are not fans but who go to games with friends who are, frequently find the excitement generated in fans by a baseball game inexplicable. Outsiders and critics frequently speak of the need to "speed the game up" to make it more exciting. Non-fans find the constant flow of statistics from radio announcers deadly boring. The fan, characteristically, has a difficult time explaining why it is that baseball excites him. He is liable to say something like, "If you really knew the game and really followed a team through a season, then you would see how exciting it is." This is a valid observation; the more one knows of the subtleties of the game and of the "statistics" which attach themselves, like Homeric epithets, to individual players, the more exciting a given situation in a game becomes. For the devoted fan, there are so many things to be kept in mind at any given instant in the course of the game, that the pace seems almost too rapid; to him it seems that dozens of meaningful dramas are being enacted all at once. But you will note how much his basic explanation of why the game attracts him sounds like the explanation my friend reported when he asked the aborigine about the significance of the sacred ceremony.

There are difficulties raised by discussing sports institutions in this manner. For one thing, the attitudes of those who participate in them may be quite different from those of people who are simply spectators. Obviously, as we have noted, not everyone in our society is deeply interested in one or another of the large organized sports. Given fans, moreover, will also value given characteristics which may not be important to others. One is familiar with coachly remarks about how sports build the competitive spirit. If one believes that building competitive spirit is a proper enterprise, sports serve to dramatize that value. But it is certainly possible to be a fan without seeing competitiveness as a good in itself. And one might want to differentiate between the ability of these sports to produce what might be termed "desired psychological states" and the reasons for which they are valued. "Desired psychological states" is an especially tricky concept. It is easy enough to observe that fans enjoy being excited, absorbed or gratified, that "rooting" involves psychological release of some sort, and so forth. One might speculate about whether all cultures produce institutions which allow behavior of this sort. If they do, it would suggest 
that the needs which this behavior satisfies are in fact universal, not cultural. But the desire for these psychological states is generally a different thing from the manner in which support for the athletic institution is rationalized. It is the difference between saying, "It makes me feel good," or "It lets me get away from it all" and saying, to pick some of the varying statements one will hear from different people, "Athletics build strong bodies and strong minds," "Athletics develop leadership qualities," or to pick a more sophisticated comment made by a social scientist who is also a sports fan, "Athletics provide an arena for certain experiences which the society values elsewhere." This might be called "the playing fields of Eton" thesis.

One can draw the same sort of distinction in examining American religious behavior. Organized religion poses difficult problems for the student of the sacred in our culture, perhaps because both its nature and its status have changed so dramatically and rapidly during our national experience, and because it is used in so many ways by different Americans. My own students seldom think to mention it during discussion of sacred institutions; undoubtedly for many other people, however, it is most important, and probably does serve to reinforce sacred (in our special sense) values. I bring it up here to suggest that the same distinction between desired psychological states and rationalizations which we noted in discussing baseball seems to apply: concern for moral guidance or for personal salvation are different from the more aesthetic effects of participating in and observing ritual, or of singing, though in theory they are supposed to be related. It is also true that for given individuals the church is more important for the social status which affiliation and attendance bring than for either of the other reasons. Note, however, that the association of social status with church membership is not necessarily incompatible with the other reasons. A person who has changed his affiliation from Baptist to Episcopal might have done so because he felt he had "arrived" socially, because he found himself theologically in better agreement with his new church, because of the physical proximity of the church building, or because its service gave him more pleasure. All four might apply, with or without apparent hypocrisy.

We are not going to discuss religion as a sacred institution. The topic is too complex for the present study, and I especially want to avoid analysis of the peculiar obsession with salvation which characterizes so much of the history of Christian sects. I mention the subject as a reference point, to suggest that its uses, like those of athletics or the arts, could be divided into the ideological, the social and the psychological.

I would suggest that the elite arts are another area which we might tentatively label "sacred." We who believe in the elite arts all feel, for example, 
that Los Angeles or Kansas City or Toledo ought to have a major symphony orchestra. As in the case of organized athletics, one can probably break down the reasons for this feeling into two general categories. On the one hand, for music lovers there is the matter of the "desired psychological state" which listening to music is felt to produce. On the other, there is a wide range of reasons which will vary from person to person. ${ }^{8}$ For some people, presumably, the art is valued primarily in terms of status-"a major league city ought to have a major league orchestra." Related is the idea that it is good to be "cultured," or to be associated with a place or group which supports cultural events. The university where I teach supports composers in residence, and though it's difficult to find anyone who has ever heard any music which they have written, no one thinks it a scandal that the State of Kansas pays their salaries. It does not strike us as strange that a nonprofit organization devoted to the dissemination of inexpensive recordings of concert music should speak of its product as "ennobling." The undergraduate who has an elective space in his program and who has noticed that some of his friends dig one or another of the fine arts is frequently moved to take an introductory survey himself. His decision may be understood as social change, even if he does not show off the knowledge he has acquired, in that sociologists now recognize that in a society in which large numbers of people fall within a middle range of income, social class to some extent must be determined not by income alone, but also by such variables as style of life and taste. But the student who picks up a taste for a new elite art feels that he's become a better person in the process. Now there are all kinds of variables which he may express which affect the art he chooses. He may speak of contemporaneity (which may lead him to cinema), or he might insist on looking at black art because he feels it more "relevant" for himself as a Negro, but there is not much variation in what he will.say that it does for him.

Let me list a number of different ways in which our feelings manifest themselves. In each, one notes that art is felt to be a separate and discrete realm of activity, one that is good for the individual and one which reflects merit on the society which produces it. This seems to be true whether or not one believes that the government should do more in support of the humanities and the arts in general. One frequently hears arguments from the analogy of European governments, which underwrite cultural pursuits rather more extensively than ours does. You will find some people who

\footnotetext{
${ }^{8}$ Some years ago the author did a study of the development of tastes among concertgoers which covers many of these matters in some detail: Stuart Levine, "Some Observations on the Concert Audience," in The American Culture/Approaches to the Study of the United States, ed. Hennig Cohen (Boston: Houghton Mifflin, 1968), pp. 296-311. See esp. the postnote on p. 311.
} 
say that the arts should not be artificially supported; that any art, such as opera or concert music, which cannot pay its way in the marketplace, should be allowed to die, that the arts which are truly meaningful to our culture are those which naturally pay their own way-cinema, the various forms of commercial music and so forth. But then they will argue that these arts are performing the proper functions of arts in the society and doing the same job which the advocate of the elite arts feels that his arts perform. The idea that art is special and worthy is not challenged. Like the Australian aborigines, in short, we get pretty vague when ask ed to explain what our "sacred" institutions are for, and wind up revealing what we really believe we and the world around us should be like.

I came across a passage in Cash's Mind of the South in which this very good intellectual historian said that the true measure of the worth of a society is the quality of its artistic and philosophical production. Because he felt that the South, in the period under discussion, had produced practically nothing in these fields, he concluded that southern society was not worth much. Now I certainly don't want to put myself in the position of defending the antebellum South, nor do I want to single out Professor Cash for castigation. The attitude he expresses is extremely common, and could be found overtly or covertly in almost any intellectual historian, among many American Studies practitioners and, for that matter, among any in our society who value the humanities as well. My point is simply that the attitude is extraordinarily widespread, and that it is not a universal truth. It is peculiar, for the most part, to modern western cultures.

A rather ugly joke which circulates among my American Indian friends might help illustrate its cultural nature. I think I first heard the story from the anthropologist Nancy Oestreich Lurie, but I have been told it several times since, and it seems unusually good evidence of the prevalence of the idea that the arts bestow merit on the groups which produce them: A black youngster and an Indian kid are arguing. The black kid says, "Who ever heard of a famous Indian musician or baseball player?" (Note the choice of fields, by the way-they're both what I've suggested as "sacred" areas.) "Why don't you Indians get on the stick and make some contributions?" To which the Indian is supposed to respond, "Ever see anyone play cowboys and niggers?" The black youngster, you see, buys the idea that you score points in heaven by producing art. The Indian kid, whose culture is not ours, does not.

A corollary of what I've said about the place of the arts in the culture is that we understand them as a separate entity. When a Navajo sand painter produces a sand painting and an elite critic sees it, we are liable to get praise of the boldness of the conception, the striking stylization, the 
symbolic abstraction, the sure use of the medium, the thrusting horizontals and the juxtaposed diagonals. Our critic, in other words, sees it as an art work, and brings to bear on it the procedures in which he has been trained for evaluating art works. The Navajo doesn't see it that way at all. Characteristically, the sand painter was called in to cure an ailing child. To him the painting and the act of producing it are at once art, religion, medicine, magic and science. He does not separate them because his culture does not separate them. Sensitive writers from Thoreau to Marshall McLuhan have been pointing out to us that one of the peculiarities of our culture is that we compartmentalize and specialize. Most non-western cultures do not; they see the universe, man and the supernatural as an organic whole. One can relate this to all manner of peculiarities in postRenaissance western culture-our belief in achievement (specialization is a very good way to produce achievement), the fact that universities are divided into schools and departments, or our characteristic way of approaching any problem-the process which involves hypothesis and investigation. "Research" is probably the sacred area which enacts this process.

It is probably a good idea to point out that in taking the position that our feelings for "research" or "expanding the frontiers of knowledge" are cultural, I am not trying to argue that the pursuit of knowledge is unworthy. But it seems to me that one of the secrets of doing cultural study of one's own culture is to learn to see that things one believes in can be culturally determined. ${ }^{9}$ One can go on believing in them, as I do. A key test, often applied in topics discussed in this essay, is the reaction of foreign visitors to our country. It happens that those foreigners with whom I come into most frequent contact are exchange students and educators primarily from countries in the western world, Latin America and Europe in particular, people, in other words, who come from cultures which also share postRenaissance concepts regarding the merit of acquiring new knowledge, the formulation and validation of hypotheses, the open-minded attitude necessary for an honest evaluation of new data, and the other attitudes which surround the idea of investigation. Even they are greatly struck by the strength with which these ideas appear in American culture. A very long and thoughtful letter from a German student of mine now completing a graduate degree at a prestigious German university seems especially telling. In comparing higher education in Germany and the United States, he points to some of the factors one would expect-the continental practice, for example, of allowing evaluation of the student's competence to

\footnotetext{
'John M. Rosenfield makes the same point-that to understand the art of another culture, we need to know the values in which it was set, and our own web of values-in "The Arts in the Realm of Ideas," Daedalus, 98 (Summer 1969), 837-43.
} 
ride not on the day-by-day or week-by-week performances in classroom situations, essay reports and so forth, but, for the most part, on a series of examinations following the completion of a body of work which the student for the most part does on his own. He says that while this would seem to promote greater freedom and flexibility, in point of fact, students feel very strongly that they are operating within a system of knowledge which is already fixed. Nothing in his graduate education in Germany, he reports, corresponds to the attitude he found again and again in seminars in the United States, namely, the professor's assumption that the area which the class was investigating was one in which the answers were not fully known, that the class had, as a sort of collective enterprise, the task of exploring new ground, and the formulation of hypotheses which could then be tried out, on appropriate data, through methods which the class itself would devise.

Similarly, an Argentine educator told me that while she felt there were a number of extremely distinguished scholars and researchers in numerous fields at that nation's most prestigious university, that it succeeded less in teaching students "how to think for themselves," "how to lay out a reasoned attack upon a problem, and carry it through to completion," than did even many of the most modest of American colleges. "The very best student thinking," she told me "goes on not at the University [of Buenos Aires], but over at the profesorado [a normal school in Buenos Aires]." She told me that I had to come in as a guest lecturer for a few weeks at the profesorado to see the difference in the students (I was, at the time, a Fulbright professor in Argentina). I followed her suggestion, and can report that it is my impression that she was correct. Interestingly enough, the profesorado has been much more heavily influenced by the United Statesin the form of faculty members trained here-than have either the University of Buenos Aires or the University of La Plata, my reference points in checking the validity of her assertions.

It seems clear that the idea that a basic purpose of education is training the students to "think for themselves," "to develop the ability to formulate a problem and design a manner in which to attack it," is closely related to the ideals that motivate research. It is assumed that the procedures of research are valuable even for those who will never use them to make actual contributions to the world of ideas. Exposure to them makes one a better citizen, more rational, more able to cope with the decision-making process in any area of human life, less vulnerable to dead ends and frustrations. This argument, along with the one about pushing back the frontiers of knowledge, must also be understood as part of that portion of our value system which justifies what I would like to call intellectualism. But, as we will see when we come to discuss ways of visualizing the structure of our 
value system, ideas such as thinking for oneself, making one's own decisions and so forth, can also be used to justify what one would have to call anti-intellectualism, which, curiously, also quite clearly has a place in any schematic representation of our system of values. I don't find this fact distressing; a value system need not be free of contradictions. ${ }^{10} \mathrm{We}$ must bear in mind that we are not trying to arrive at a logically consistent philosophical system, but rather to develop a method for describing a system which presently exists and which can be observed.

Perhaps this is just another way of saying that the student of a culture who has a grasp on what we are calling its sacred value system ought to be able to handle even areas of disagreement in terms of conflicts between the corollaries of the same basic values. Many of my students, for instance, are currently questioning the wisdom of certain University regulations. Many, for example, resent having to take laboratory sciences or mathematics courses as part of their graduation requirements. Those who defend such requirements say that such programs are valuable even for the student who is never going to use them directly because they give him the ability to define workable procedures to solve complex problems, or because they produce the kind of mental discipline which is invaluable in handling issues in any walk of life. "Nonsense," the students retort, "do you have any evidence to show that people who have had Mathematics 2C function any better as historians, as art critics, as politicians, as businessmen?" It seems very clear that both sides are appealing to the same set of values in stating their arguments. On both sides it is assumed that a certain set of learning experiences - though there is disagreement as to the set-will fit one better for coping with life after the formal educational period is completed.

And on the most basic level, the idea of education in our country seems related to what most of my students agree is the single most fundamental value in our sacred value system, a value which they variously call "the orderly universe" or "process." Both a humanist, who would subscribe to the set of ideas we have discussed in explaining how the elite arts are justified, and the scientist, whose ideals might most readily be approached through the concept of research, in other words, agree that the proper functioning of a society depends upon the success of the educational structure to inform and to teach methods of clarity in thought which work because the universe is susceptible to rational analysis. I am deliberately

\footnotetext{
${ }^{10}$ Ralph H. Turner writes, "Only when social values may be called upon to support contradictory patterns of behavior in actual situations can we speak of social disorganization," "Value-Conflict in Social Disorganization," Sociology and Social Research, 38 (May-June 1954), 301-8. I think he assumes that value systems "ought to be" a little more consistent than they ever are. It is difficult to conceive of a society in which values would not be available to justify both sides of a dispute.
} 
stating this in very vague and general terms in order to avoid the many debates possible within these basic values. I particularly want to avoid that kind of debate which centers around our ability ultimately to make human behavior and motivation rationally understandable and even predictable. Both sides of that debate, it seems clear to me, are carried out through the framework of the same values.

Some Sacred Values: The set of values listed below was derived in the following manner. First, a group of institutions was identified and tentatively labeled "sacred" through the process of reasoning just described. Artifacts of each were examined, using for the most part the traditional tool of content analysis. "Values" were defined somewhat loosely as "things which are fundamentally true," "attitudes which it is felt desirable to inculcate," "goals which are unquestionably worthy" or "directions in which we should, ideally, be moving." There are some semantic difficulties here; obviously, a value is not necessarily the same thing as a goal or attitude. ${ }^{11}$ But it was felt desirable to spread the net fairly widely and then to derive recurring values by boiling down the data, by seeing what our evidence from various sources had in common, rather than beginning with a tentative list of values which we expected to find. An idea would be considered a value only if it kept showing up consistently in place after place, and only if it seemed so basic as to be insusceptible of contradiction.

The list of institutions tentatively identified as sacred-the elite arts, organized athletics, higher education and "research"-is not in any sense intended to be comprehensive. There was a fair degree of certainty that each of the institutions named was felt by its "users" to be a very good thing, deserving of support, and exemplary of characteristics which were felt to be desirable. The reader will notice that our procedure follows very closely the model suggested in Figures 1 and 2.

The "artifacts" examined were the following: in the elite arts, a wide variety of surveys of the histories of the different arts (somewhat arbitrarily limited to the arts in the United States) from a number of different periods. We looked at early surveys of American literature, painting, architecture and music, at surveys written late in the 19th century, early in the 20th century, and within the last two decades. We also examined critical studies of different arts written at varying periods, and finally looked to contemporary newspaper and magazine accounts which ranged

\footnotetext{
"Good definitions of "values" and related concepts appear in Mr. Turner's essay cited above. He is commendably sensitive to difficulties which result from mistaking the absolute formulation typical of values for the actual behaviorally relevant content of the values (p. 306).
} 
from reviews of specific events to commentaries about the state of a given art in a given period or place. Particular attention was paid to the process by which standard canons have been established in each of the arts, on the theory that the "validation process" would be an unusually good place to see the basic values at work in a period. The "validation process" is the process by which is decided which are the "major" or "important" works or artists. ${ }^{12}$ No attempt was made to follow good sampling procedure. The early studies of the arts in America are small in number, and it was possible to examine almost all of them. But the number of works on the arts in America multiplies astronomically in the 20th century, especially in the field of literature, so the means of selection was pretty much catch-as-catch-can.

To gain a foothold in higher education, we decided to use the introductory sections which appear in most college catalogues in which a statement is made of the ideals of the institution. The first time we tried this, we made no attempt to achieve a good random sample. The idea grew out of a class discussion, and we simply decided to send each student off to the library to examine half a dozen catalogues of colleges and universities of "varying sorts." We checked only to be sure that there was no duplication of schools. I tried the idea again a semester later using a properly designed random sample. We took a list of higher educational institutions in the United States, decided that each student would handle half a dozen, multiplied the number of students in the class by six (there were ten students), divided the number of institutions by sixty, selected a random starting place in the list and went to work on our sample. Results were substantially the same as in the first go-round.

The procedure for organized athletics was far less systematic. A colleague is currently doing a study of values in college and university ath-

\footnotetext{
${ }^{12} \mathrm{Mr}$. Rosenfield argues, "In our country, clearly, there is no agreement on a single, fundamental value system by which we judge what is good and bad in the arts ('The Arts in the Realm of Ideas,' p. 839)." Our findings suggest that there is a clearly understood group of sacred values which are always used to "validate" what is good and reject what is not. But the values themselves are not a logical system; the same work can be both validated or rejected through judgments based upon the same group of values. We were repeatedly impressed with the relative stability of the group of values. Even when critic A praises a work which critic B despises, critic A rarely attacks critic B's values. Instead, he typically applies a different condoned value, one which can be used to praise the work. For example, the Hudson River landscape painters for years were considered unimportant: their work was not technically innovative; they pioneered no sweeping changes in world art history, etc. Their works are currently studied seriously because "they accurately expressed national feeling for nature and the American environment." Indeed, new evidence sometimes makes possible praise based on the same values previously used to condemn: the same painters "innovated curiously in adapting a bird's-eye point-of-view quite unique in the history of landscape painting." Innovation, indigenousness and innovation again, in this example, are used to evaluate the same works.
} 
letic departments; his results will be interesting to see. What I did was simply suggest to the students that they examine a wide variety of sports material from newspapers, magazines and sports publications. Several students transcribed the comments of radio and television announcers during sports events. The results were pooled informally in a round-table situation.

Our approach to "research" was deliberately limited. Certainly an investigator concentrating on this problem would want to include material from a wide range of research institutions. Because time was limited, we decided to examine introductions to the concept of research method which are presented to college undergraduates. And so we looked at prefatory material and at lead chapters of textbooks in elementary courses in the sciences and social sciences.

This description of procedure is intended to reveal frankly the tentative nature of much of our data. It would be fair to say that our work in the arts was far more thorough than our rather arbitrary samplings of material from other areas. To put the matter informally, all we were trying to do was to see whether our hypothesis about values, "sacred" values and "sacred" institutions seemed workable. And it would be a fair assessment of the current state of this line of investigation to conclude that, as of now, the idea seems fruitful. Values recur; the institutions at which we looked seem to stress the recurring values. It is time now to discuss the values themselves.

The values which we derived from the study recurred frequently enough for us to be quite certain that they are felt to be basic, and, in the special sense of the word, "sacred." We were unsure, however, of how relationships between them should be indicated. All are closely related, and some seem to be corollaries of others, but it is hard to tell which are most "basic," or where one concept leaves off and another begins. The most satisfactory model I have seen was one prepared by a student in my class (see Figure 3). It worked better than any of the others we were able to create, and so I present it here with the comment that all of us (including the student who developed it) were able to see things that were wrong with it, areas in which the ranking is relatively arbitrary, and so forth. ${ }^{13}$ Definition of some of the terms used in it would be in order before discussing the chart. But one should bear in mind that the definitions will themselves overlap.

\footnotetext{
13"The arranging of values in hierarchies of importance is an effort to conceive in rational terms the situational specificity of values" (Turner [see note 10], ibid.). Turner is describing why people, in arguments, want to rank values. What we were about was quite different: we were not trying to settle a dispute, but to group, in a systematic manner, values we had found operating in our "sacred" institutions.
} 
Figure 3. An Arrangement of Sacred Values.

1. Orderly Universe

or

Process

9. Fair Play

10. Individual Potential

11. Talent or Genius

12. Self-Expression

13. Creativity

14. Innovation

15. Diversity

16. Indigenousness

17. Naturalness

18. Humanitarianism
8. Meliorism

2. "Truth"

3. Objectivity

4. Broadest view possible

5. Knowledge

6. Education

7. Specialization

Compartmentalization

Intellectualism

\section{Sanctity of Human Life}

1). Orderly universe. The world is taken to be comprehensible in its structure. Although my students were well aware of the persistence in our culture of occult means for understanding the universe, they nowhere encountered, in the material examined, points of view contradictory to the idea that the world is put together through a series of comprehensible bonds and processes. Indeed, the student who produced the chart considers "process" synonymous as a value with "orderly universe." Some students put it differently; in the words of one, this is the belief that "rational thought works." Faced with something we do not understand, we apply certain processes which we call collectively "rational thought," and the procedure is supposed to work. It might be a fair critique of our entire study to say that our culture, on the sacred level, thinks of itself (if a cul- 
ture can be said to think) as a rational entity, and that all we have done is to spell out the tenets of that rationality. Perhaps, quite by accident, we will end by deriving Descartes from the texture of our own artifacts.

2) Truth. If the process derived from (1) is applied properly, and adequate information is available, truth will result. We may be sure truth is real, replicable, susceptible of scientific testing and verification. It is also "good" and an end in itself. Moreover, the process by which it is found and confirmed seems to outrank all other processes in sacredness. Its sacredness is revealed in prototypical story patterns which could be said to serve the function of myth. If someone recounts the story, let us say, of how the Catholic Church reacted to the work of Copernicus and Galileo, we all respond by feeling that the Church was wrong to attempt to suppress "truth." If we encounter someone who does not perceive the sacredness of truth or of the process on which its establishment rests, we assume that he is inadequately educated; the process itself will cure him.

3) Objectivity. The ideal attitude for those in quest of truth. It is also good, in the quest, to achieve

4) The broadest view possible. This means considering as much reliable data as can be gathered. ${ }^{14}$ And this is the reason that

5) Knowledge is good in itself. It "expands human horizons," though in acquiring it, one may not immediately see its utility, and it may be dangerous if misapplied. The process of acquiring it, however, is good for one; it builds proper mental and even moral attitudes, and increases one's personal worth. Moreover, one never can tell to what good uses any knowledge may be put by future investigation. Participating in the process is honorific and self-fulfilling. The process is at the heart of educational theory. Thus all open-minded and dedicatedly-supervised

\footnotetext{
${ }^{14}$ American Quarterly's commentator, in suggesting that I devote further space to "demonstrating that each of the sacred institutions . . . does in fact manifest the values listed," asks, as an example of the sort of questions he has in mind, "just how does the 'broadest view possible' manifest itself in athletics?" I can think of any number of ways on any number of institutional levels in sports. A few examples will have to suffice: 1) It is "cutting time," and the coaching staff in any team sport meets to decide which players must be dropped from the squad to meet league regulations. By which criteria should the staff attempt to make its difficult decisions? 2) It is late in a baseball game, men are on first and third with one out, a good left-handed batter is due up, and the pitcher, who is most effective against right-handed batters, is clearly tiring. With the ace reliever complaining of a sore elbow, the pitching rotation skewed by a busy schedule and a 17-inning game yesterday, and with a crucial double-header scheduled tomorrow, by what criteria should the manager, with a one-run lead (one could, and indeed should, go on listing factors to be considered), make his decision on whether to pull his starter? Or position his infield? 3) You are seated in a greasy bridge-chair in the cluttered interior of a gas station and sundry shop in a small town waiting for a flat to be fixed, and the "old boys" in wool plaid jackets who use the place as a club are discussing the teams involved in recent and not-so-recent World Series with an eye to determining which showed the most overall strength. By what criteria do they press their cases?
} 
6) Education is good. It puts students in touch with the great traditions of human learning, and enables them to feel it possible to play a role in expanding outward the "frontiers of knowledge," or in improving the human condition (see 8, Meliorism). One's sense of role here seems to be the equivalent of what other societies achieve through their basic religious myths. One can feel that one is playing a part in the process even if one's life work is humble, for one can feel that one's work supports the process, if only by making it possible for others to play loftier roles.

7) Specialization, compartmentalization and intellectualism are necessary. They accelerate the process, but they carry with them the dangers of narrowness and other-worldliness. The specialist's education should be broad enough to counter these dangers, but even the comically narrow specialist may make a great contribution to "progress" or "human betterment."

8) Meliorism. The most basic "radical" concept in the value system. It is assumed that it is within the power of man to alter and improve human institutions, and that this alteration can favorably affect the quality of human life and even human personality. To me it seems that this value more than any other distinguishes our perception of the world from that of the other cultural complexes. A radical student who lives in a commune told me that his decision to live there was an attempt to get outside "the whole rotten value system," to live in an atmosphere of honesty, directness, simple "natural" emotional experience, recognition of individual worth and so on. To me it seemed, first, that the things he named as good were completely within the value system in its most "sacred" sense, and second, that the idea of changing and redesigning a social institution as basic as the family could only occur to someone who believed fervently-as most young radicals do-in the idea of meliorism.

For clarity, it might be worth mentioning that meliorism is by no means exclusively an American idea-none of these values is. We share it, for example, with all communists; Marx is nothing if not a meliorist and a believer in "process." So, by definition, are all socialists, political theorists and reformers. If there is a peculiar national flavor to our versions of the sacred values of western culture, it may be the result of the extremely broad base on which our national commitment to meliorism rests. One finds it in the literature of the near and far left, to be sure, but it is no less prevalent in the literature of the extreme right which I have examined. It is an issue on which an SDSer and a Bircher would agree: changes (of the right sort) would make things better. Rather than escapees from the value system, the more serious young radicals, hippies and social experimenters seem to me self-conscious but often sincere missionaries, holy hermits and saints to what is most "sacred" in our value system, call- 
ing us not to escape from it, but rather to live up to it. It is not surprising that their heroes in our intellectual history-Thoreau and Whitman especially-are men who quite consciously set out to play the roles, respectively, of radical saint and bard to the most sacred values of the culture, especially meliorism (Thoreau's redesign of human institutions is a sort of one-man utopian community, or, if you will, a one-man commune) and to the group of values which follow.

9) Fair play. A parallel idea to objectivity. It is to human relationships what objectivity is to intellectual pursuits. Just as bias, prejudice or unequal manipulation of information are felt to impede the quest for truth, so "unfair" treatment of people is felt to impair the proper operation of society or human institutions. Violations of fair play are bad because

10) Individual potential must be allowed to express itself. Any man, regardless of his heredity or social status may possess

11) Talent or Genius. These are felt to be real, and society is at fault to the extent that it thwarts their maximum creative expression. Indeedand here we come to the reason that the arts and the other areas we have named are probably "sacred"-one ultimately judges the worth of a society on the number of great creative figures it produces and encourages. Much of our fiction, biography, autobiography and, on a humbler level, sports literature is based on a moral pattern which can be described very simply: the story is sad if talent or genius is thwarted; it is happy if genius thrives and creates. That pattern has to be a basic myth of our culture.

Corollary to (11) are belief in (12-15).

12) Self-expression. Since each man is unique, he should express his "real self" or fulfill his personal potential.

13) Creativity. In any field, this is taken to be a sign not only of innate capacity but of mental health. It is taken to be almost a desired trait of personality, and is sanctioned as such. Institutions or people which thwart it are felt to be bad and in need of alteration or education.

14) Innovation. This is a corollary not only of the fair-play complex of values, but also of the orderly universe-process complex. Innovation is valued not only because each "contributor" is unique, and thus should do something different, but also because each field is understood as a process, which should progress.

Although, as I said, these values overlap to the extent that any attempt to name them is somewhat arbitrary, and an attempt to explain how they are felt to be related involves what looks like circular reasoning, a discussion of them is not simply an exercise in tautology. The values are not universal; they are cultural. Innovation is not universally valued. Within the African culture which produces it, the carved wooden object is not valued for the individual expression and innovation which the carver brings to it (though 
we may value it, or him, for such reasons). It is valued because it has the correct characteristics. He made it right, and it therefore performs the right religious function. When, earlier in the 20th century, a Hopi village lost the last old man with the proper clan membership, power and knowledge to create certain ritual objects and conduct an important ceremony, it delegated the job to a tribesman who endeavored with great conscientiousness to perform the tasks properly. He fasted, prayed, purified himself, made the objects and conducted the ceremony. It failed to work; the rains did not come, the crop failed, the people starved. We might praise him for his creativity and innovation; the objects he produced might seem very beautiful to us. But he knew with some bitterness that he had failed to do his task correctly; our values, innovation, personal expression and creativity, would seem totally irrelevant to him.

15) Diversity. If change ("process") is felt to be normal, if innovation is sanctioned, and if each individual is felt to be unique, diversity will also be sanctioned, as I believe it is on the "sacred" level of our value system. Once again we are dealing with an area of concern to rebels-against-thesystem, one of whose credos is "Do your own thing." Once again, however, it seems clear that the radical ideology is rooted in the sacred value system. It would be an incomprehensible slogan in a society which did not already carry the family of interrelated values (10-15) which might be lumped together under the heading "Individualism."

16) Indigenousness. Perhaps this is too specialized an idea to merit a position in a list of values, but it is felt to be a corollary of the same family of values, and since it is important to our feelings about the arts, I want to include it. An art form is felt to have a certain intrinsic worth on purely aesthetic grounds, but it is looked upon with special favor if it seems to grow from the special characteristics of its creators. In numerous fields, elite critics at least since the Federal period have called for works which grow from the national experience. A "distinctively American" painter, composer or novelist is to be especially treasured. The call for regional arts was similarly based upon the value of indigenousness. Jazz is valued not merely for its quality, but because it is a form which developed here. It gains special sanction for being the creation of black Americans. If we examine the literature which deals with jazz, from scholarly articles by jazz historians to novels and films, we find clear evidence of the relationship between indigenousness, worth and value 9, fair play. It is felt to be unfair that jazz, created by black musicians "indigenously" out of the grim experiences of black life, has brought relatively little fortune to its creators. And, to anticipate a point we'll get to in the final section of this essay, appreciation of jazz is taken as a sign that one has become in some sense "enlightened." 
17) Naturalness. I am not satisfied with "naturalness" as a name for a value, but no other term I can think of is sufficiently broad. The idea of course overlaps (12), self-expression, but also includes sanctioned traits of personality, frankness and openness. It includes as well an idea perhaps best stated negatively: anti-hypocrisy. And it can be used to justify antiintellectualism, as a basis for an argument that an intellectual approach to a given issue is "artificial" or "phony."

Intellectualism, however, is also sanctioned under the family of values which deal with the orderly approach to the world, with truth, objectivity and specialization. This is, perhaps, a good time to repeat the point that the sacred value system is not a philosophically reasoned, highly logical construct. It is rather a set of principles on which belief seems to be founded on the "sacred" level, a set of ideals toward which an "enlightened member" of our culture feels all processes should move. Its corollaries very often contradict one another when several apply to a given problem.

Consider the case, for example, of the next corollary of the idea of fair play.

18) Humanitarianism. This seems related to the idea of individual worth (10). One wants to help the unfortunate because all men are worthy. One knows that many people get less than an "equal break"; humanitarianism might be defined as the effort to apply fair play to human relationships. It is related to another sanctioned personality trait, "sympathy for the underdog." But there can be a conflict here, for (10), (11), (12), (13) and (14) all stress achievement. A football fan thus may feel a conflict when watching a game between a weak team and a strong one, loaded with "stars." Assuming that neither is the fan's favorite team, and that the outcome of the game does not affect his team's standing, he may find himself hoping the stars will shine, while at the same time hoping that the weak team will somehow win.

Conflict of a more serious sort can develop when the subject is not a "morality play" such as athletics, but "real life." Thus it is possible to argue on humanitarian grounds for government action to prevent racial injustice while still feeling the force of a state's rights argument, let us say, for local determination of school integration policy. Both sides of the debate are rooted, ultimately, in the concept of fair play-evidence of the pervasiveness of the sacred value system. The "enlightened" citizen's feeling toward the man who used the state's rights argument in this instance would be that prejudice, or inadequate experience, or inadequate education (as in Figure 6) prevent him from seeing that arguments based on human worth, underdog-sympathy and fair play outweigh those based on diversity, individualism and indigenousness, particularly when the 
diversity, individualism and indigenousness of only some citizens are in fact being protected. ${ }^{15}$

In Figure 3, these values are arranged in what is admittedly an arbitrary way, with Process or Orderly Universe at the top as being as near a key to the others as could be devised, with those values related to individuals or groups of people set to the left, and those related to knowledge to the right. ${ }^{16}$ Meliorism is accorded a central position because it seems almost as much a "given" as "Process"-indeed, process and "progress" come close to merging in many of the sources we examined-and because it seems to link the two larger groups.

19) The sanctity of human life also had the quality of being a "given," and also seemed best in a central position because of its relationship with the two larger groups. It means something special in our culture, and does not appear, at least in this special form, in all cultures.

Herman Melville pinpoints the difficulty for us with terrible precision in Moby-Dick when he points out that if we really believed in an afterlife, we would not feel so grief-stricken at the loss of loved ones who should be going to their eternal rewards. That we are utterly inconsolable shows that we really do not believe. Melville, characteristically, follows this passage with one in which he mockingly reassures us that faith, like a jackal, preys amid the tombs and will ultimately overcome even this grief. What he is implying, for our purposes, is that belief in the importance of the sanctity of human life is corollary to an essentially rational and secular view of the universe.

Since the majority of Americans were trained in a religious world view which we can loosely label "Christian," it is difficult for them to see that Christianity's enormous emphasis on personal salvation is peculiar when compared to the position of other world religions. Judaism places relatively little emphasis on salvation, and the mystical religions which still occupy a majority position among the world's population do not draw nearly as

\footnotetext{
${ }^{15}$ Such conflict, obviously, does not have to be so strong as to produce anomie or social disorganization (though it can). See note 10 above.

${ }^{16}$ American Quarterly's commentator writes, "This list is . . . very close to the longer lists developed by Robin Williams in his chapter on values ["Values and Beliefs in American Society," esp. pp. 469-70] in American Society (New York: Knopf, 1961) and by John Gillin in his article "National and Regional Cultural Values," Social Forces, 34 [Dec. 1955], 107-13. If Levine's list was developed independently of such attempts this would be of interest." A very good point (see note 5); it was developed independently. Indeed, I have made a conscious attempt to protect my ignorance of studies of values developed from other methods, not from hostility to such methods or to the social sciences ("Some of my best friends are social scientists"), but in order to avoid prejudicing my thinking and that of my students. We wanted to develop our own list; awareness of pre-existing lists would probably have influenced our work in that we would have had given values in mind before studying our evidence.
} 
strong a line between life and death as does Christianity. This is not to say that Christian churches may not be functioning for many people in our culture as sacred institutions. I believe that for many people they do. It does seem to imply, however, that from the point of view of the Christian, the sacred values of our culture seem to exert a secularizing influence. I do not believe that the game of applying rational and logical criteria to the heart of Christian belief has been played in our culture only by gifted skeptics like Melville or Mark Twain. It is also a popular sport among those of my friends who are ministers, priests, and nuns.

And, interestingly, even those who attack the secularizing tendencies, fundamentalist Protestant clergy, for example, make use of precisely the same procedures which are corollary to the list of values listed in Figure 3 on the right-hand side. We have once again a good example of how conflict within a cultural unit can be understood in terms of the corollaries of basic values.

The relationship between secularity and belief in the sanctity of human life shows very clearly in an anecdote I read or heard somewhere, and which I am perhaps retelling inaccurately-I simply can't remember where I encountered it. I am sure that I have the basic outline right: In a period of grave drought and food shortage in India, an American attached to AID or some comparable agency is working in India with an Indian government official to expedite the rapid distribution of American grain and other foodstuffs. Time is desperately important; enough data are available to make it clear that unless the food reaches its destination very quickly, millions of peoplee will die of starvation. The American is at his desk night and day, organizing, arguing, pleading, cajoling. His Indian counterpart, highly educated, personally agreeable and a good friend of the American, in contrast puts in a normal workday and enjoys his leisure time in his customary pursuits. The American endures this sort of behavior as long as he can, but finally feels that he must light a fire under his friend. He yells at him and tells him that he can't understand how he can go about his normal routine in a time of crisis when the lives of millions of people depend upon the extra effort he is unwilling to expend. "Don't you realize that if we don't get this done in time, two and a half million people are going to die?" "Yes," replies the Indian, "people die. Didn't you know that?" Death is simply not as tragic in many other cultures as it is in ours, and the reasons behind our special feelings about death are rooted in our sacred values.

Some Speculations on Value Change and Social Structure: What good to us as Americanists is the procedure outlined in this essay? The pedagogical answer seems fairly clear: to the extent that I am right in my supposi- 
tions (and I have tried to label as tentative those portions of the argument of which I am less than certain), it gives us a firm way to handle the problem of art and values, and a way of seeing the arts as a group of social institutions among many. An editorial reader for this journal provides a summary of my argument:

a) (Social) institutions operate in terms of values some of which are "universal" and some of which are cultural.

b) (Cultural) values which recur in all (or most) of the institutions of a society are its basic or "sacred values." Actually, they are only "sacred values" if they seem basically true and good [on the most condoned level]. Such values form one basis of thought, evaluation (and action).

c) Institutions which are especially loaded with sacred values and/or which can be seen as a kind of "morality play" involving these values, and which are not devoted to immediate mundane matters can be labeled "sacred institutions."

d) People are likely to have difficulty explaining the nature of these institutions since they are not directed to immediate practical problems and because the basic values they embody are largely taken for granted.

e) Examination of a wide variety of American institutions yielded a list of four seemingly sacred institutions. [Others undoubtedly exist.]

f) Analysis of the values in these (and other institutions) led to the ... [preceding] list of "sacred" American values.

Our method should be useful in a number of ways. It does suggest, for instance, a method of determining which segments of our national population constitute subcultures (clearly within the ecumene in that the same sacred values serve as guidelines) and "alien" cultures (geographically American, but with markedly different sacred values). I am not, by the way, suggesting these values as a kind of loyalty test, nor in any way endorsing the idea that groups such as tribally-oriented Indian people, who, by this criterion, seem to me outside the ecumene, should be brought within it. ${ }^{17}$ But the use of the list, or a better one if one can be devised, could bring some salutory precision to what has been an exceedingly loose and sloppy debate about "rebellion against the whole rotten value system" (the "rebels," however, uniformly believing in every sacred value on the list) and the separateness of certain ethnic "cultures" (which seem to me admirable and worthy of "pride," but very clearly within the ecumene; subcultures, not alien cultures, laying stress on indigenousness, fulfillment of potential and fair play in particular).

There are large numbers of phenomena in our society which seem based on values which obviously are contradictory to the values which we have

\footnotetext{
${ }^{17} \mathrm{My}$ ideas on this subject are spelled out in "The Survival of Indian Identity," in Stuart Levine and Nancy Oestreich Lurie, The American Indian Today (Baltimore: Penguin, 1970).
} 
named and to their apparent corollaries. I do not believe, however, that these are "sacred" values. "Sacred" describes concepts which are simply true and precepts on which one ought to act. Let me use an illustration. I spent a summer in California working with a group of "turned-on" students on this problem of values. One young lady did a paper for me on something called "hard rock protest music." She had a tendency to see the object of the protest as a cultural value, instead of seeing that the song itself in its protest was expressing a value which was felt (at least by the songwriter) to be "truer." For example, if the song complained about some form of racial discrimination, she named racism as the value. I would not argue with her contention that our society is and has been racist, but the value which the song expresses is the opposite-something which we might call "fair play." Similarly, a song which complains about conformity cannot in any sense be taken to prove that Americans are conformists. What it shows more clearly is that the author of the song believes in individualism.

There is another, related issue which good students will raise if we do not raise it first: it is the matter of direct relevance. What can the study of institutions and values tell us about issues we face? Can it help us to create models of social processes which will do us any good in deciding where we are, and what we should do?

It seems to me that the key to constructing successful models of the American social system is dynamicism. We need dynamic models not so much because values change over time (they do, though I think sacred values change very slowly) or even that institutions change (they do, too), but largely because individuals change, often quite rapidly, as broadened social, intellectual and artistic experiences produce series of crises in beliefs and perceptions, creating "gaps" between geographic, social, ethnic and generational groups.

I have, as a result of a series of studies my students and I have done, hard evidence that such dynamic change is characteristic of the experiences of individuals who enjoy the various arts, and as this essay was originally conceived, I took a few pages to speculate about whether such changes in taste were analogous to changes elsewhere in our national experience. I asked in effect whether the concertgoer who began his listening career, say, hostile to concert music, then came to like the familiar high-romantic composers, and whom I had interviewed at a concert of previously unperformed contemporary Belgian chamber music, had not been influenced in his development by the same sorts of social forces and the same group of condoned and validated values as, let's say, the enlightened Supreme Court justice who at one stage of his career had been a member of the Ku Klux Klan. I think he had; both seem examples of dynamic change on the individual level. Indeed, I would argue that both 
represent social change as well, and that any social model which cannot handle the kinds of change represented is far too rigid to reflect American social realities. So the study of institutions and values leads very quickly indeed to major issues.

What I have said in these last paragraphs is not intended as a defense of the status quo, nor as a sermon on the virtues of "working within the system." I include it because it seems to me that the scholar whose own work bears a vital relationship to the world around him is duty-bound to point out that relationship to the best of his ability. I do not intend even a defense of our sacred value system as I perceive it. But it does seem worthwhile to point out that the tendency to rhapsodize about the beauties of cultures very different from our own by way of criticizing ours is silly and misinformed. I am not sure cultures can be "rated" by any absolute criteria. The criteria we are tempted to use are liable to be themselves based upon our own cultural value system. An exotic (i.e., foreign) culture seems more harmonious than ours, let us say. But it is also smaller, far more homogeneous, and so racist that its racism denies even the possibility of the humanity of outsiders. Another demonstrates a beautiful blend of art, ritual, belief and behavior. But its social structure is rigid beyond our ability to endure restraints. No alien culture I can think of will do as a model for us; we may learn from them, gain detachment and perspective from knowing them, but I fear we shall have to work out our own salvation. To me it seems enormously hopeful that our own values of truth, objectivity and fair play have forced us into the present agony of selfanalysis. If we are presently unsure of whether the system is working, we may be sure that the value system is.

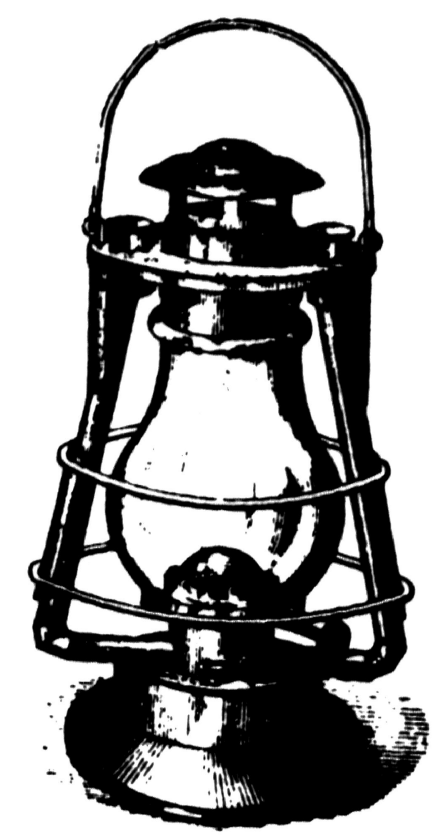

